This is an Open Access article, distributed under the terms of the Creative Commons Attribution licence (http://creativecommons.org/licenses/by/4.o/), which permits unrestricted re-use, distribution, and reproduction in any medium, provided the original work is properly cited.

doi:10.1017/So1 44686X17000228

\title{
Squalor, chaos and feelings of disgust: care workers talk about older people with alcohol problems
}

\author{
LIS BODIL KARLSSON* and EVY GUNNARSSON*
}

\begin{abstract}
Older persons with alcohol problems have today become an all too common part of everyday elder care, but research in this area is still scarce. This article has a Swedish context with the aim of describing and analysing home care workers' narratives about older people who can be characterised as heavy drinkers, i.e. people with severe alcohol problems who need considerable care for extended periods. Limited knowledge is available concerning this age group. This article therefore fills a knowledge gap about home care workers' perspective about body work and the abject, and breaches the myth that older individuals should be able to drink as they prefer and/or notions of drinking alcohol as a last enjoyment in life. The care workers talked about how they got drawn into the daily lives of the care recipients and how they ended up in situations where they, on the one hand, removed the consequences of drinking, and on the other, felt that they sustained the drinking by cleaning out dirt and washing the care recipients' bodies.
\end{abstract}

KEY WORDS - care work, abject, body work, alcohol.

\section{Introduction}

The consumption of alcohol has increased among older people in Sweden. Persons aged between $6_{5}$ and 80 years are drinking more wine and beer today compared with previous generations. In particular, women of this age group have increased their consumption of wine, with a $5^{\mathrm{o}}$ per cent rise between 2004 and 2011 (Ramstedt and Raninen 2012). Among the oldest old -77 years and older, both men and women - the weekly alcohol consumption has increased (Kelfve et al. 2014). Some alcohol addicts, who in the past did not expect to live beyond retirement, today

* Department of Social Work, Stockholm University, Sweden. 
need adequate care. Others, who may have been moderate users during working age, can develop extensive drinking habits in their old age, due to retirement, bereavement, isolation, etc. (Gunnarsson 2013; Hanson and Gutheil 2004; Royal College of Psychiatrists 2011). Older individuals with alcohol problems have today become an all too common part of everyday home care, but research in this area is still scarce. Neither gerontology nor alcohol research has focused on severe alcohol problems in this population group, even though we live in an ageing society (Gunnarsson 2013; Hanson and Gutheil 2004; Johannessen, Engedal and Helvik 2015; Jyrkämä and Haapamäki 2008). Drinking alcohol may by definition not be considered a stigma, but an indication of wealth and power (Room 2005 ). However, there appears to be severe stigmatisation of people suffering from alcoholism when the alcoholism is considered a wilful act, and not an illness or a mental disorder such as depression or schizophrenia (Schomerus et al. 201 1; Sorsdahl, Stein and Myers 2012). The risk of stigmatisation might hinder people from seeking help (Schomerus et al. 2011). However, recent research indicates that there may be a shift from negative attitudes towards alcoholism among professionals to a more neutral, even a positive, attitude compared with the 1980 os and 1990 (Crotherts and Dorrian 2011; Howard and Chung 2000). This acceptance can be explained by an understanding of alcohol abuse and dependence as a disease, and not as a lack of morality (Howard and Chung 2000), as well as by an understanding of the role of genetics in alcoholism (Ducci and Goldman 2008).

The focus of this article is older people with severe alcohol problems in home care services in the region of Stockholm, Sweden. Sweden has publicly financed welfare services with provision of universal welfare for its citizens. Every senior citizen has the right to apply for assistance from the municipal elder-care services. After assessment by a local government official, often a qualified social worker, the older person may receive assistance according to their needs (Szebehely and Trydegård 2012). Home health-care services, once approved for an older individual, may include assistance with practical chores, such as cleaning and laundry, personal care, such as help getting dressed and undressed, and other care such as assistance with moving (National Board of Health and Welfare and the Swedish Association of Local Authorities and Regions 2015). Swedish elder care is based on the principles of client self-determination and autonomy, and of providing good care, which does not include offering any treatment when alcohol problems are an issue (Gunnarsson 2013).

The work of home care workers is often described in relational terms; however, it is also described as a job in which ageing bodies need to be cared for, with duties including, for example, handling excrements and 
washing clothes (Sörensdotter 2008; Trydegård 2005). Care work is real body work, according to Twigg (2006), since it involves bodies and bodily functions, as well as daily routines, such as getting up and going to bed, washing and dressing, eating, drinking, visiting the toilet, and so on. Body work is an occupational category in Twigg's (2006) view. Regardless of whether the recipient of body work is called client, customer, patient or service user, the work involves touching, cleaning, manipulating or managing the body of the other. This type of care work has been described as 'dirty work' (Twigg 2006) or considered as work involving the 'abject body' (Kristeva 2007).

The aim of this article is to describe and analyse home care workers' narratives about older people who can be characterised as heavy drinkers, i.e. people with severe alcohol problems who need considerable care for extended periods, requiring care workers to dedicate both time and extra effort at work. Limited knowledge is available concerning this age group. This article, therefore, fills a knowledge gap about home care workers' perspective about body work and the abject, and breaches the myth that older individuals should be able to drink as they prefer and/or notions of drinking alcohol as a last enjoyment in life (Gunnarsson 2012).

\section{Care work for older individuals with alcohol problems}

Both Swedish and international research studies on the daily care of older individuals with alcohol problems are rare. Research on older people's alcohol problems and the role of care work in the Nordic countries is modest (Gunnarsson 2013; Jyrkämä and Haapamäki 2008; Koivula et al. 2016). The few existing studies, however, all point in the same direction. In 1986, Cronholm conducted the first and only Swedish review of research on older people with alcohol problems so far (Cronholm 1986). At the time, there was no knowledge of the extent of the problems in home care services, of methods used to deal with them or of municipal policies, formal or informal, on services for older individuals with alcohol problems. The responsibility was put on the care workers, who often solved problems individually and virtually ad hoc, without any training concerning alcohol problems. Later Swedish studies have confirmed these conclusions (Gunnarsson 2012, 2013).

Most Swedish home care workers caring for older people with alcohol abuse problems lack special education on alcohol and older people and have largely been left to their own devices to handle this aspect of their work (Gunnarsson 2012). In practice, home care workers face various dilemmas in their job with individuals with alcohol problems; however, an overall strategy tends to be to build relationships of trust and, thereby, to 
try to reduce harmful drinking in the affected individuals (Gunnarsson 2012). In another study of home care services, in the Stockholm region, regarding their potential to handle alcohol problems, it was clear that care workers as well as social workers rarely have any training in dealing with older individuals with alcohol problems (Gunnarsson 2013). There are few, if any, care units or care providers with expertise in this area. Cooperation between care workers and substance misuse teams has been documented for only a few of the studied regional municipalities (Gunnarsson 2013 ; see also Gunnarsson and Karlsson forthcoming).

According to the 2015 Swedish Board of Health and Welfare report, only about one-third of municipalities in Sweden co-ordinate care for older people with abuse and addiction problems (National Board of Health and Welfare and the Swedish Association of Local Authorities and Regions 2015). As in earlier investigations, the absence of an explicit municipal policy on how to handle requests to purchase alcohol for individuals with alcohol problems is evident (Gunnarsson 2013). Practice in municipalities varies from not providing alcohol to older people at all, to providing it to all care recipients who request the service (Gunnarsson 2013). In summary, the research suggests that care workers lack adequate training about serious alcohol problems among older people, at the same time that they are de facto forced to address these problems in their daily work.

The limited research findings from Sweden resemble findings from Anglo-Saxon countries. In a British report with the striking title "Our Invisible Addicts", the authors stress that there is 'a pressing need to address substance misuse in older people' (Royal College of Psychiatrists 2011: 6), not only because of the increasing number of older people in general, but also because the percentage of individuals drinking within this age group is on the rise, with severe negative physical and/or mental health consequences. More emphasis on health and social care services can therefore be expected in the future. A lack of knowledge could lead professionals within the health and social care services to interpret symptoms such as hypertension, incontinence, falls, depression, cognitive problems, self-harm and diabetes as being age-related rather than as symptoms of underlying alcohol abuse (Royal College of Psychiatrists 2011). The same report stresses that there 'may be problems in joint working between specialist teams, particularly where patients 'fall through gaps in service provision' (2011:34). Some professionals maintain that older people are too old to benefit from treatment for abuse, although no reasoning is provided to support this notion (see also Cummings, Bride and Rawlins-Shaw 2008). Others refer to the client's right to self-determination or to client privacy and intervention is considered as a violation of these principles (Simpson, Williams and Kendrick 1994). 
When Herring and Thom (1997) examined policies concerning purchase of alcohol by home care workers for older clients in three areas in London, they uncovered a lack of written guidelines. Care workers may fail to intervene in cases of alcohol abuse because they lack management support and because few services exist for older people with alcohol problems (Herring and Thom 1997). A study of home care workers in Scotland found that developing relationships and building trust with clients was important in enabling home care workers to deal effectively with alcohol abuse while still respecting their clients' right to self-determination (Millard and McAuley 2008). Another study from Scotland examining the experiences of a care team for older people with alcohol abuse found that the team did not have a co-operative working relationship with the substance abuse team. In short, the social workers on the older people's care team lacked knowledge of the problem and did not know that there were any alcohol abuse services for older people (Shaw and Palattiyil 2008).

Viewed together, Swedish and international studies show the need for research on older individuals, alcohol and care work. Research suggests that professionals who work most closely with older people with drinking problems seldom have adequate knowledge of how to identify alcohol problems and, further, how to approach them. In practice, care workers have to develop their own approach and trust in their personal judgement. The right to selfdetermination is recurrently described as an obstacle in this context.

\section{Care work as 'body work' and the concept of the abject: theoretical perspectives}

Drawing on Twigg (2006) and Kristeva (2007), we will analyse care workers' narratives on their experiences of older people with severe alcohol problems. To conceptualise the importance of the body in care professions, Twigg (2006) uses the term 'body work' ('the body work of care') and discusses social care and personal care as integral parts of the care profession, care work involving each of body time, domestic time and service time.

Body work, according to Twigg et al. (2011: 179), 'involves work on both an object body and a subject person, but routinized and standardized health and social care practices construct the recipient of care as tractable and predictable, transforming their bodies into appropriate objects of labour'. The 'body work of care' is dirty work; referring to Douglas' and Miller's discussions on dirt and disgust (Douglas 1997; Miller 1997), Twigg writes:

Care work is dirty work in a direct and obvious way, dealing as it does with the less attractive aspects of the body that result from sickness, frailty and decline - with incontinence, vomit, sputum - substances emitted from the body of a polluting 
character and widely associated with disgust and social revulsion. (2006: 136, our emphasis)

Western cultures lack tolerance for bodily fluids and odours (Kristeva 2007). By extension, social care workers are perceived as 'polluted' and their occupational status is low, according to Twigg (2006). The care work is supposed to be performed behind closed doors for the sake of protecting not only the client's dignity, but also the professional status of the care worker. Still, care workers are sometimes regarded as community refuse workers, since our youth culture does not engage with death, dirt and decay (Twigg 20o6). It should be added, however, that good intentions based on the 'desires of agencies to protect the status of clients by not putting too strong an emphasis on the bodily nature of their needs' are one reason for keeping the body out of public discourse (Twigg 2006: 121). The avoidance of and also the silence surrounding the topic of body work can be explained by the current cultural expectation that the functions of the body take place in seclusion, i.e. behind closed doors (Twigg 2006). The essence of personal care is, according to Twigg, that an individual gets help doing what they are supposed to do in privacy: going to the toilet, washing and dressing. Needing help with personal care erodes any person's status. The relation between a care worker and a care recipient is asymmetrical and also contradictory, because it requires that two complete strangers interact. The intimacy is involuntary and discordant since both parties are violating social codes. The other person is totally dependent on the care for survival (Twigg 2006). The precarious relationship between the involved parties can be an important explanation for the lack of research in the area (Twigg et al. 2011; see also Storm 2013).

As previously mentioned, Twigg, when referring to care work as 'dirty work', includes reference to 'the abject body'. The term was originally coined by Kristeva (2007) to refer to the need of every human being, continually and over time, to remove and reject 'filth' and 'dirt' in order to stay alive. Urine and faeces are considered unclean, and so is vomit. Every person must reject these 'defilements', which Kristeva terms 'abject', to survive physically.

Not only the body and bodily fluids, but also people can be perceived as abject, Kristeva argues. A human being who is seen as abject is considered repelling and abnormal, and is therefore regarded as taboo or unclean, and cast off. Such a person can also be perceived as threatening, upsetting the balance between people. The abject person, in other words, exists outside human and social community, according to Kristeva (2007). Further, the concept of the abject refers not only to the phenomenon of dirt, but also to encroachments on the expected order that lead to chaos: 
'It is thus not lack of cleanliness or health that causes abjection but what disturbs identity, system, order. What does not respect borders, positions, rules. The in-between, the ambiguous, the composite' (Kristeva 2007: 4). A human being who is perceived as abject is an outcast, and is therefore excluded from the social community. Someone who is abject is neither subject nor object. According to Kristeva (2007: 4), this person is a nonsubject, a non-object, neither human nor animal. Using the different characteristics of the abject as a point of departure, the narratives of home services personnel about the drinking problems of older people will be presented. The care workers portrayed life as an endless, filthy existence and described how drinking among these older people can arouse disgust. Moreover, they described how these older people disrupt the expected order. In fact, they create chaos in everyday care work. However, it is striking that even if the care workers describe the abject, they keep a non-judgemental and an empathetic attitude towards their care receivers. The selected theoretical perspectives of body work and the abject capture phenomena that are difficult to comprehend, phenomena that people normally tend to avoid or consider to be unclean, such as the bodies of older people, in general, and the bodies of older people who are drunk, in particular.

\section{Methods}

The present study was carried out through focus group interviews (Gibbs 1997) in the Stockholm region. The interviewed care workers had each been assigned duties in home care services, some of which involved providing care for older people with severe drinking problems. The participants were home care workers (assistant nurses or home helpers) employed in elder care and working in older persons' homes. Three focus group interviews were carried out with home care workers, in all 18 participants (three of whom were men), in the three selected municipalities (out of 26 municipalities in total), situated within the Stockholm region. The proportion of men who provide home services in Sweden is relatively small; 17 per cent of nursing aides and 7 per cent of assistant nurses are men (Statistics Sweden 2015). The youngest participant was in her twenties and the oldest was close to retirement. The selection of care workers must be regarded as a convenience sample since interviewees were asked by supervisors whether they could participate in a focus group on the day on which the interview was scheduled. The selection cannot be said to be representative of the population of care workers who provide home care as a whole. Rather, the study aimed to gather knowledge about the experience 
of the care workers. Although focus groups have the character of an informal conversation (Karlsson 2008; Kitzinger 1994; Stewart, Shamdasani and Rook 2014), an interview guide was used to keep the focus on the participants' experiences and understanding of taking care of older individuals with drinking problems. The questions focused on: How does one come to an understanding of when care recipients had problems with drinking alcohol? Which physical and mental problems and complications are affecting the life of the care recipients? In other words, the questions in the groups specifically focused on older care recipients considered as heavy drinkers, i.e. individuals who are severe and long-term problematic alcohol users.

When describing the situation of the care recipients, the participants distinguished whether an old person's problem was due to ageing, for example, or to sickness, medication or their severe drinking problem. It goes without saying that some care recipients vomit or are incontinent due to illness or ageing. The essence of this study is the consequences of problematic alcohol use. The conversations were recorded and then transcribed verbatim without editing. The analysis drew on the phenomenological approach of thematising data and the method of meaning condensation was used (Kvale and Brinkmann 2009). Each transcribed text containing meaningful units was categorised into relevant themes. After reading the transcriptions, four overarching themes recurred in the transcriptions. The first theme focused on the homes of these older individuals, while the second involved descriptions of the drunken body of the care recipients. The third theme concerned the care workers' perception of disordered procedures and the fourth theme focused on specific encounters with care recipients who were drunk. Further, the analysis was in a next phase focused on what Braun and Clarke call 'define and refine', i.e. 'identifying the "essence" of what each theme is about (as well as the themes overall), and determining what aspect of the data each theme captures' (2006: 92). Critical examination of the collected empirical data in the last phase of the analysis is based on the care workers' body work (Twigg 2006) and the abject (Kristeva 2007). The choice of theoretical concepts emerged out of the process of analysis and was therefore not made beforehand.

The research process was guided throughout by ethical principles (The Swedish Research Council's Expert Group on Ethics 2011). Interviewees were assured that participation in the focus group was voluntary and that they would be able to withdraw from the study at any time ( see Gustafsson, Hermerén and Petersson 2011). Since the group discussions focused on how participants perceived working with older people with severe alcohol problems as a group, there were no data listing the conditions of individual 
care recipients and therefore no ethical approval. Neither do we present any interpretations that may reveal identities or cause offence. The focus of the group interviews was socially vulnerable people, often with multiple problems of alcohol and physical/psychological age-related disorders, and their support needs. This suggested that extra ethical caution would be required. Information that, put together, could reveal an identity must not be mentioned (Kvale and Brinkmann 2009). To avoid this risk, some superficial changes to the participants' statements before quoting them are made. It is possible that individual care workers may recognise their care recipients in the material, despite the precautions; however, we are certain that the material will not reveal any identities to third parties. Indeed, during the focus group interviews, the participants were themselves very careful to avoid details that could identify a person to the researchers, such as names or specific personal information. They talked warmly and with empathy about their care recipients and were careful to differentiate between the older persons as individuals and their respective problems with alcohol. At the same time, they did say that everyday tasks were complicated by the complex and sometimes very specific needs of these care recipients with severe drinking problems. The focus group participants also clearly stated that they wanted to talk about their experiences with this group of care recipients to place these issues on the political and academic agenda.

Whether the older individual's alcohol consumption should be considered as misuse/abuse or addiction to alcohol is not essential to this study, especially since the interviewed home care workers did not differentiate between these terms. Instead, the focus during the talks was on the life situation that the care workers discussed, i.e. the situation where severe drinking has serious consequences for the care recipient's physical and/or mental health, as well as negative consequences for their social situation, and therefore influenced their work as carers. In those instances where care workers used the term 'addiction', the word of their choice is chosen.

\section{Findings}

\section{The homes of the care recipients - descriptions of squalor}

As Douglas states, the threshold marks the boundaries of the home and can give 'expression to so many forms of entries' (1997: 163). The care workers interviewed recurrently summed up in one word what they faced when crossing the threshold into the home of an older individual with alcohol problems: squalor. Especially the amount of accumulated garbage and empty bottles everywhere and food left uneaten in the fridge were indicators 
of a severe drinking problem. The homes were described as 'stinky', with the smell 'ingrained' in the place, the furniture and floors stained and grimy, and ashtrays filled with cigarette butts. The homes could be said to be dirty and messy, with filthy bathrooms and heaps of unwashed clothes and unwashed dishes everywhere because of the state of drunkenness of the care recipients. These older people's homes were also described as unsanitary and characterised by 'general sloppiness'. They were 'as dirty as it can get, [with] layers upon layers', filled with a stench because of 'all the garbage everywhere'. In one woman's home, the care workers found 'big burn stains on the bed, on the floor, on the plastic mat' after she had fallen asleep while intoxicated.

Altogether, the homes were described as shabby and decrepit because of the residents' long-term alcohol problems: 'It's so disgusting there that even the parquet floor is lifting. You see, it's so dilapidated in many of these homes that you get the feeling that there are bugs creeping and crawling in the furniture'. One care worker, Carol, said that the home of an alcoholic 'stinks most of the time; perhaps they have urinated on the carpets, the armchairs, and they are smokers too'. In the face of circumstances marked by squalor and chaos, the care workers may feel disgusted. Visiting the homes of the older people with severe alcohol problems was not uncomplicated, and often it was fraught with a sense of filth:

Carol: The moment you shut the door, you simply want to turn on the shower because you feel disgusted, you see.

Moderator: Disgusted because?

Carol: $\quad$ Disgusted because - of lack of hygiene and cleanliness.

Diane: You feel dirty. You want to get out of your clothes and take a shower.

Sometimes the care recipients declined the service, and as the care workers could not 'force an entry into the home' they got turned away. Thus, opportunities to help and clean or ensure that the older people ate their food were hampered: 'They [periodic drinkers] would often meet us at the door and not let us in', as assistant nurse Emmy explained. If the old individual refused to open the door or let anyone in at all, then the workers left without accomplishing their mission and/or just left a boxed meal at the door:

Joy: They often close us out, a little bit. When they really get like this, when it really gets this way, they often have periods where they get really drunk, they often want to meet us at the door and not let us in.

Moderator: But then how will you help them?

Joy: They say no thanks.

Vic: $\quad$ They say no thanks. 
Joy:

So they receive the boxed meals during these periods. Then you can't just force your way in, you can't do that. So sooner or later you find them lying on the floor, and then you can step in.

Vic: Yes, you have to break in.

Closing the door in the face of the home care worker, having a fit of anger or refusing help when being drunk can be understood as inefficient ways of drawing a line vis-à-vis the care worker (see Twigg 20o6). When allowed entry to the home of an old individual with alcohol problems, the care workers are sometimes greeted with invectives, and often with strong odours and destitution. The care workers emphasised that some of the old people sometimes tried to hide their problematic situation out of shame, but also out of necessity, e.g. because of being afraid of being evicted because of the state of their apartment. Although the older care recipients tried to hide their drinking problem, they found it hard to keep up a front to the care workers.

According to Twigg (2006), personal care involves helping another human being with a personal matter, which is expected to take place in privacy. Intimacy is not desired and both parties must make clear and delimit this involuntary situation (Twigg 20o6). On the other hand, one would like to stress that when a human being is severely drunk, she or he has trouble drawing the lines. In itself, intoxication is a form of boundary crossing since the persons are incapable of taking care of themselves and their living space. General notions of the meaning of home as secure and private are shattered when thinking of care recipients as isolated, even as prisoners in their own homes because of their severe alcohol problems and their dependence on care. In such cases, the home is no longer a sanctuary. Rather, the individual is tied to the home. In their homes, the care recipients can drink as much as they like.

\section{The intoxicated body}

The descriptions in the focus groups revealed that it was not just the homes of the older drunk individuals that were dirty and filthy, but also their bodies. Sometimes they were incontinent or even doubly incontinent as a consequence of their alcohol consumption: '...doesn't manage to get to the toilet, and is too drunk to understand', as nursing assistant Carla described; or as one care worker, Theo, put it, 'We are there so they won't choke on their own vomit'. Others likewise described the lack of hygiene, saying, for example, 'They are not that clean or fresh-looking either, not having washed themselves, and the same shirt for 14 days'. An 
intoxicated body can arouse disgust if it is perceived as limp and if it spreads a particular smell. Whitaker explains that particular odours are expressions of boundlessness, because 'they extend beyond the individual's physicality and thereby impinge on and transcend other people's boundaries and spaces' (2005: 103, our translation). The intoxicated body could be described as dissolving in dirt. Often, a care recipient's body was broken as a result of drinking, because falling was unavoidable in the inebriated state the care recipients were in, and then their bones were fractured:

Camilla: They fall and the shoulder bone is broken. They return [from hospital], have a drink and fall again, breaking the other shoulder or the same again. They never heal, as it were.

Alex: Or when they lie there covered in vomit and - pardon the expression shitty, vomity, and totally wasted.

The older care recipients were actually harming their bodies with alcohol, according to the participants: 'They jeopardise their own health [by drinking alcohol]', said one care worker (Judy), who further emphasised that older people shorten their lives and end up bed-ridden because of their alcohol problems. When a person in care is overweight and has fallen while being intoxicated it is sometimes impossible for the care workers to lift them back on to the bed or wheelchair. Then the rescue services have to be called in. A nursing assistant mentioned the case of one woman who wet her sanitary towel on purpose:

It's tragic and inconceivable, because she absolutely can't - she refuses to go to the toilet. She, she, she ... you know, she is so unhygienic that she is covered in sores. Really, it's misery beyond belief. (Debbie)

At the same time the care worker's work to eliminate the traces of the woman's drinking continued, this included traces on her intoxicated body: 'We in the home care service, we'll go, let's wash this, and it's clean again and she can't see that she has vomited. So we wash her and she doesn't know that she stinks'. All this was done on the care recipient's terms and sometimes their terms collided with the workers' explicit request for a proper bed, for instance, so they would not have to stand bent over the bed, or a request for a loading lift to facilitate heavy lifting. One nursing assistant, Dominique, summed up the situation as follows: 'We work in their homes - on their terms'.

Ageing bodies, and especially intoxicated bodies, cannot physically survive without personal care. Because of the circumstances of the older care recipients with alcohol problems, the bodily and social degeneration is more pronounced, or, as Kristeva puts it, 'There, I am at the border of my condition as a living being' (2007: 4). The words 'repelling' and 'repulsive' have 
been used in the interviews to describe an ageing and intoxicated body. Kristeva explains, however, that it is not the absence of health and cleanliness that transforms the body into an abject body, but the borders and rules that are transgressed, or clouded as in the case here when the care workers involuntarily become enablers of continued destructive drinking. According to the care workers interviewed, these care recipients upset the notion of a good life for old people living in a welfare state, a theme that will be further investigated under the next heading.

\section{Wreaking havoc and disruptive behaviour}

Even if there were not that many drinkers among the care recipients according to their care workers, only about a tenth of the care recipents, those who drank definitely increased the workload, at least during periods of severe drinking. A large part of this was due to the stress and worry that the care workers suffered when faced with their situation. Ambivalence emerged during the discussions when the home care workers talked about being tasked with administering life-saving medicines such as insulin, while they could never prevent the destructive drinking of the care recipients. Nor is this prevention the task of the home care worker - even though the drinking can affect their working conditions. Care workers' working hours are limited, and so are their assignments and responsibilities. The participants admitted that they were constantly caught in a dilemma. The drinking could only continue with the help of others - whether or not the home care workers bought alcohol, there were always resigned relatives, naive neighbours and obliging taxi drivers who would provide the care recipients with alcohol: 'They [the taxi drivers] work in a service profession too, and if they receive an assignment then they'll purchase alcohol for their customers', as one participant said. The interviewees described that in their encounters with care recipients with alcohol problems they constantly faced various dilemmas, and often they were forced to make choices that they would prefer not to make:

Louisa: Regarding these particular users you could probably say that you wish it would go a different route. Simply put, that we [in home care] would receive other support, so that they [the care recipients] will get support from elsewhere. Because like I said, what we do there is just enabling.

Pierre: We reinforce their addiction.

Louisa Yes.

Pierre We don't solve the problem.

The conversations in the focus groups clearly indicate that the home care workers preferred the care recipients to stay sober, irrespective of 
whether they thought that severe drinking was due to a disease or not, since the care recipients' state of drunkenness considerably increased their own workload. Some did, however, add that it was acceptable to have a drink or a limited amount of alcohol to aid sleep at night. Others stressed that older people should not drink at all, saying it is 'not good for them', especially because most old people have multiple medical problems, are physically weak and are on medications.

The abject person exists beyond all human and social communities, according to Kristeva (2007). The concept of the abject does not only refer to the phenomenon of dirt but also to encroachments of the expected order that lead to chaos. It also became clear during the focus group discussions that care recipients with severe alcohol problems did not meet expectations in terms of what older people should be like and the lives they should be living. The care workers stressed that older people should not have an undignified life created by alcohol problems. The care workers mentioned that, in a welfare state like Sweden, older people are not expected to live under unworthy conditions - conditions that could even be defined as squalor and chaos - caused by drinking problems. The picture of misery upsets common conceptions of what life in old age should be like, according to the care workers interviewed. As one participant, Zahra, exclaimed, 'My God, look at all the unseen deprivation'.

\section{Involuntarily drawn into their world}

The focus group interviews highlighted that visits by care workers to older individuals with alcohol problems took place behind closed doors. However, the drinking did not escape the care workers eyes; also, as the care recipients got used to their care workers, they grew less withdrawn and timid about drinking openly. However, they dreaded the world outside, especially fearing that outsiders should catch them in the act of drinking. Irrespective of a care worker's feelings and preferences, the care worker was drawn into the care recipients' existence because the care recipient depended on the care worker and often also because of worries about the care recipients' physical/psychological vulnerability and social exposure when drinking.

According to the participants, to encounter these care recipients can be experienced as emotionally draining and it can also evoke anger, especially if the drinking problem is seen as 'self-inflicted'. While the individuals depend on the care workers for their survival, the care workers feel pressured, because of time pressure, and sometimes admitted that they feel that they become enablers of the care recipients' severe alcohol problems. 
Nursing aide Suzy described the situation as problematic, saying that home care workers 'only maintain the addiction, [even if they] try to ensure that the [care recipients] do not get booze'. The workers expressed that they felt their hands were tied, and that they must find an approach to this work aspect in line with their duties:

At the same time, it's very hard to be placed in a situation where we enable the addiction. You know, an addiction is an addiction and sitting there sustaining it is no fun. But rules are rules. We can only follow them - whatever we think or feel. (Celia)

Sometimes an ambulance has to be called in or at least a district nurse to assess the older individual's health state. Some interviewees stressed that these older people had ended up 'between the cracks', because society pretended the problem did not exist: 'nobody really cares', as one care worker said. As another focus group participant put it, care workers 'keep them [the care recipients] afloat'. Because of the care workers' responsive approach to the individuals with severe drinking problems, the relationship sometimes became very close:

You see - we're a part of the closed room. It's what's outside that's the hard part. We're a part of it - we make their existence possible in the first place ... they tell us everything. They tell us more than they tell their family. (Aida)

As previously mentioned, the focus group participants discussed whether it was actually their job to help old people deal with severe drinking problems. Several participants felt that qualified staff members who have chosen, and are specifically qualified, to work with people with alcohol problems should be involved, i.e. social workers from, for example, substance abuse teams. However, the care workers were aware of being in a Catch-22 situation because if they did not help, who would actually help these individuals with severe alcohol problems? Old people with alcohol problems need help and the reason for their drinking should be evaluated, according to the participants. For example, mental illness might be a cause and the care recipients may have no self-awareness of their situation. Nursing assistant Wilma commented that problem drinking 'is a disease just like diabetes or cancer'.

In the view of those interviewed, it was not up to the home care services to provide treatment for problematic use of alcohol. What the care workers did have to do was to make sure that the recipients had a tolerable life situation and ensure that they were not totally deprived. During the focus group interviews, the participants stressed that services with unique competence were available within the community for persons with special needs, such as teams working with dementia or mental illness. It would, therefore, be reasonable to expect that there should be teams with knowledge of how 
to work with individuals with severe alcohol problems. In other words, the participants did not hold a negative attitude towards this group of care recipients, but stressed their own lack of enough competence and the negligence of society.

Kristeva (2007) suggests that not only bodily fluids, but also people, can be perceived as abject. Her theory does not specifically focus on the intoxicated body but it nonetheless helps us understand the care workers when they talk about older people with alcohol problems. A human being who is seen as abject is cast off and is considered repulsive. Such a person can also be perceived as threatening, disrupting the balance between people and the expected order. Since the care is provided in a closed room beyond our view, great demands are placed on the care worker's professional conduct (Twigg 20o6). The seclusion contains a further paradox as the alcohol problem is veiled for family members and other persons close to the older people. The care worker, however, always encounters the uncensored reality and removes the worst traces of misery and indicators of severe alcohol problems by cleaning the home and washing the care recipient's body. Seclusion means that the problem remains hidden from the gaze of others. Older people with severe alcohol problems can therefore be said to exist in a borderland. Nobody really seems to care, except their care workers. The participants felt that they were unavoidably being dragged into the world of these care recipients.

\section{Discussion}

Based on Twigg's (2006) and Kristeva's (2007) arguments, one can interpret the meaning of the home care workers' narratives of care recipients with severe alcohol problems. They described care work as dirty and the abject body, for example when it included cleaning vomit and excrement as a consequence of the individual being intoxicated. These bodily fluids are associated with social revulsion and disgust. In relation to Twigg's (2006) suggestion that the Western culture lacks tolerance of bodily fluids and odours, one can note that the care workers encountered an 'uncensored version' of the existence of their care receivers. That is, they encountered it even before other professionals were called in for an emergency situation or in connection with the deteriorating mental and/or physical health of these care recipients. Twigg's (2006) ideas on body work and Kristeva's (2007) theories on the abject, i.e. on what people in general perceive as objectionable and dirty, can be related to the care workers' descriptions of performing a disgusting body job and to their depictions of the intoxicated individual's life situation and body. This analysis provides a 
deeper understanding of why the care workers, being at the bottom of the care hierarchy, cannot avert their gaze when they encounter these intoxicated older people in their vulnerable situation. The conversations revealed that it is not only remarkable that the care workers lack training when special expertise is required in situations involving old people with severe alcohol problems, but also that society at large seems to dismiss the care workers' assessment of situations as insignificant and negligible, unless there is a crisis. It is clear from the descriptions that the old people with severe alcohol problems are shunned to a great extent by authorities and social welfare units concerned, with the exception of the home care workers. The drinking problem and the squalor in the care recipients' homes are no one's responsibility. The result is that the responsibility stops with the care workers although they have neither the time nor the energy, let alone the competence and knowledge required to handle this problem. The situation is compounded by the lack of professional supervision.

The participants talked about their care recipients with empathy. They saw these recipients as individuals, despite their severe alcohol problems, and despite the fact that these drinking problems complicated their own work situation. The consequences of drinking for the living situation of the care recipients are remarkable, as drinking alcohol makes them live their lives in squalor and chaos. The care workers wished that the older care recipients would receive help for their drinking, but since nothing was being done to stop their alcohol consumption, the home care workers had to deal with the negative physical and/or psycho-social consequences of the alcoholism. Furthermore, they said that there should be dedicated assisted living facilities or hospital beds and teams trained to deal with older people with alcohol problems within each municipality.

Contradictorily, these care recipients would, especially during 'active periods', refuse help and any interventions; the participants argued that they could therefore hardly be considered motivated to break their destructive drinking and seek care or treatment. Swedish legislation is clear on this issue, stating that the self-determination and autonomy of the older individual takes precedence (Gunnarsson 2013). Therefore, there seems to be a vicious circle: if these older people did not drink, their situation would be improved, and the care workers' work situation would be less stressful. The older people need help for their drinking problems but do not seek it and cannot be forced to seek it. Above all, an image emerges of how care recipients may continue to fare badly-day after day, without anything being done about the reasons for their severe drinking problems. 
The value of training should not be underestimated, since training can help care workers to acquire a language and opportunities to discuss different approaches. Earlier research about specific education and skills enhancement programmes focusing on older people with mental health problems in Stockholm County, Sweden, emphasises the need to reflect during and after every encounter (Karlsson, Mattsson and Rydwik 2015; Karlsson and Rydwik 2013). The participants in the skills enhancement programmes expressed that it should not just be assumed that mental health problems explain all intentions of the client, and stressed the importance of interacting and creating mutual relationships (Karlsson, Mattsson and Rydwik 2015). We therefore believe that it is crucial for care workers to be given opportunities to receive guidance and specific training on how alcohol affects older people and their lives, and therefore this study contributes to essential knowledge.

The participants in this focus group study can hardly be described as having a negative attitude towards their care recipients or as moralising about their drinking. However, older individuals should be able to drink as much as they prefer and it is certainly not an enjoyment because of the negative consequences. The care workers distinguished the care recipients, as individuals, from their alcohol problems, even though the alcohol problems complicated their work situation. It was obvious that the participants really liked the people they provided with care-probably prerequisites for performing this kind of body work (see also Bjerregaard 2014). However, they emphasised how unnecessary they thought it was that these older care recipients should suffer because of their severe drinking.

\section{Acknowledgement}

This paper was financed by Forte, Swedish Research Council for Health, Working Life and Welfare.

\section{References}

Bjerregaard, K. 2014. The shared experience of care: a social identity approach to understanding the motivation of people who work in social care. Doctor of Philosophy in Psychology dissertation, University of Exeter, Exeter, UK.

Braun, V. and Clarke, V. 20o6. Using thematic analysis in psychology. Qualitative Research in Psychology, 3, 2, 77-101.

Cronholm, I. 1986. Äldre och alkohol. En litteraturöversikt [Old persons and alcohol. A review]. Report 62, Department of Gerontology, Jönköping, Sweden. 
Crotherts, C. E. and Dorrian, J. 2011 . Determinants of nurses' attitudes toward the care of patients with alcohol problems. Nursing, Article ID $8215^{14}$.

Cummings, S. M., Bride, B. and Rawlins-Shaw, A. M. 2008. Alcohol abuse treatment for older adults. Journal of Evidence-based Social Work, 3, 1, 79-99.

Douglas, M. 1997. Purity and Danger. An Analysis of the Concepts of Pollution and Taboo. Routledge, London.

Ducci, F. and Goldman, D. 2008. Genetic approaches to addiction: genes and alcohol. Addiction, 103, 9, 1414-28.

Gibbs, A. 1997. Focus groups. Social Research Update. Department of Sociology, University of Surrey, Guildford.

Gunnarsson, E. 2012. Dilemman och utmaningar: Hemtjänstens arbete med äldre personer som har missbruksproblem [Dilemma and challenges. Home care services working with older people with abuse problems]. In Storbjörk, J. (ed.), Samhället, alkoholen och drogerna. Politik, konstruktioner och dilemman [Society, Alcohol and Drugs. Constructions and Dilemmas]. Stockholms universitets förlag, Stockholm, 237-53.

Gunnarsson, E. 2013. Alkoholmissbruk och självbestämmande - en kartläggning av den svenska hemtjänstens förutsättningar att arbeta med äldre personer med alkoholproblem [Alcohol abuse and self-determination. An investigation of the condition within Swedish home care services]. Nordic Studies on Alcohol and Drugs, 3o, 3, $227-42$.

Gunnarsson, E. and Karlsson, L. B. forthcoming. 'Vi möter de ofrivilliga' - socialsekreterare om äldre personer med missbruksproblem [Older people, alcohol and care needs: care managers about working with older people with alcohol abuse problems]. Nordic Studies on Alcohol and Drugs.

Gustafsson, B., Hermerén, G. and Petersson, B. 201 1. Good research practice - what is it? Views, guidelines and examples. Revised version, Swedish Research Council, Stockholm.

Hanson, M. and Gutheil, I. A. 2004. Motivational strategies with alcoholinvolved older adults: implications for social work practice. Social Work, 49, 3, $364-72$.

Herring, R. and Thom, B. 1997. The right to take risks: alcohol and older people. Social Policy E Administration, 31, 3, 233-46.

Howard, M. O. and Chung, S.S. 2000. Nurses' attitudes toward substance misusers. I. Surveys. Substance Use Ẽ Misuse, 35, 3, 342-65.

Johannessen, A., Engedal, K. and Helvik, A.-S. 2015. Use and misuse of alcohol and psychotropic drugs among older people: is that an issue when services are planned for and implemented? Scandinavian Journal of Caring Caring Sciences, 29, $2,325^{-32 .}$

Jyrkämä, J. and Haapamäki, L. 2008 Åldrande och alkohol. Nordisk forskning och diskussion [Aging and alcohol. Nordic research and discussion]. NAD 52, NAD, Helsingfors, Finland.

Karlsson, L. B. 2008. More real than reality. A study of voice hearing. International Journal of Social Welfare, 17, 4, 365-73.

Karlsson, L. B., Mattsson, P. and Rydwik, E. 2015. Competence acquired. The learning process of professionals within social care. Nordic Social Work Research, $\mathbf{5}$, $2,143^{-} 5^{8}$.

Karlsson, L. B. and Rydwik, E. 2013. Doing care with integrity and emotional sensibility - reciprocal encounters in psychiatric community care of older people with mental health problems. Sociology Mind, 3, 2, 185-92. 
Kelfve, S., Agahi, N., Mattsson, A. D. and Lennartsson, C. 2014. Increased alcohol use over the past 20 years among the oldest old in Sweden. Nordic Studies on Alcohol and Drugs, 31, 3, 245-6o.

Kitzinger, J. 1994. The methodology of focus groups: the importance of interaction between research participants. Sociology of Health and Illness, 16, 1, 103-21.

Koivula, R., Tigerstedt, C., Vilkko, A., Kuussaari, K. and Pajala, S. 2016. How does older people's drinking appear in the daily work of home care professionals? Nordic Studies on Alcohol and Drugs, 33, 5/6, 537-5o.

Kristeva, J. 2007. Powers of Horror-An Essay on Abjection. Columbia University Press, New York.

Kvale, S. and Brinkmann, S. 2009. InterViews: Learning the Craft of Qualitative Research Interviewing. Sage, Newbury Park, California.

Millard, A. and McAuley, A. 2008 Alcohol and the over 65 s: service gaps seen from home care in Scotland. Journal of Social Work Practice in the Addicitions, 8, 3, 417-20.

Miller, W. I. 1997. The Anatomy of Disgust. Harvard University Press, Cambridge, Massachusetts.

National Board of Health and Welfare and the Swedish Association of Local Authorities and Regions 2015. Öppna jämförelser 2015. Vård och omsorg om äldre. Jämförelser mellan kommuner och län [Care among older people. Comparisons between municipalities and counties.] Socialstyrelsen and SKL, Stockholm.

Ramstedt, M. and Raninen, J. 2012. Alkoholkonsumtionen ökar bland äldre [Alcohol consumption is increasing among the elderly]. Alkohol och Narkotika, 3, $12,4^{-7}$.

Room, R. 2005. Stigma, social inequality and alcohol and drug use. Drug and Alcohol Review, 24, 2, 143-55.

Royal College of Psychiatrists 2011. Our invisible addicts. First report of the Older Persons' Substance Misuse Working Group of the Royal College of Psychiatrists. Report CR165, June, Royal College of Psychiatrists, London.

Schomerus, G., Lucht, M., Holzinger, A., Matschinger, H., Carta, M. G. and Angermeyer, M.C. 2011. The stigma of alcohol dependence compared with other mental disorders: a review of population studies. Alcohol and Alcoholism, 46, 2, $105^{-12 .}$

Shaw, C. and Palattiyil, G. 2008. Issues of alcohol misuse among older people: attitudes and experiences of social work practitioners. Practice. Social Work in Action, 20, 3, 181-93.

Simpson, M., Williams, B. and Kendrick, A. 1994 Alcohol and elderly people: an overview of the literature for social work. Ageing $\mathcal{E}$ Society, 14, 4, 575-87.

Sörensdotter, R. 2008. Omsorgsarbete i omvandling. Genus, klass och etnicitet inom hemtjänsten [Caring in transition. Gender, class and ethnicity in home help]. Dissertation, Department of Social Anthropology, Stockholm University, Stockholm.

Sorsdahl, K., Stein, D.J. and Myers, B. 2012. Negative attributions towards people with substance use disorders in South Africa: variation across substances and by gender. BMC Psychiatry, 12, 101.

Statistics Sweden 2015. Inom vården finns Sveriges vanligaste yrken [Within health care are the most common occupations in Sweden]. Available online at www.sverigesiffror.scb.se [Accessed 1 June 2016].

Stewart, D. W., Shamdasani, P. N. and Rook, D. W. 2014. Focus Groups: Theory and Practice. Third edition, Sage, Newbury Park, California. 


\section{Lis Bodil Karlsson and Evy Gunnarsson}

Storm, P. 2013. Care work in a Swedish nursing home. In Hujala, A., Rissanen, S. and Vihma, S. (eds), Designing Wellbeing in Elderly Care Homes. School of Arts, Design and Architecture, Aalto University, Helsinki, 148-62.

Szebehely, M. and Trydegård, G.-B. 201 2. Home care for older people in Sweden: a universal model in transition. Health and Social Care in the Community, 2, 3, 300-9.

The Swedish Research Council's Expert Group on Ethics 201 1. Good Research Practice. What is It? Report number 1:2005. Available online at www.vr.se [Accessed 21 October 2016].

Trydegård, G.-B. 2005. Äldreomsorgspersonalens arbetsvillkor i Norden-en forskningsöversikt [The care workers working conditions in the Nordic countries]. In Szebehely, M. (ed.), Äldreomsorgsforskningen $i$ Norden-En kunskapsöversikt. [Research About Elderly Care in the Nordic Countries - A Review]. Tema Nord 2005:

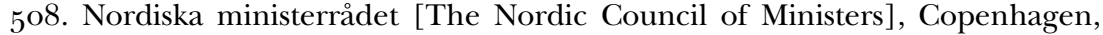
$143-196$.

Twigg, J. 2006. The Body in Health and Social Care. Palgrave Macmillan, New York.

Twigg, J., Wolkowitz, C., Cohen, R. L. and Nettleton, S. 2011 . Conceptualising body work in health and social care. Sociology of Health and Illness, 33, 2, 1 71-88.

Whitaker, A. 2005. Kroppen under livets sista tid [The body during the last period of life]. In Jeppsson Grassman, E. and Hydén, L.-C. (eds), Kropp, livslopp och åldrande. Några samhällsvetenskapliga perspektiv [Body, Life Course and Ageing. Some Perspectives Within Social Science]. Studentlitteratur, Lund, Sweden, 87-123.

Accepted I February 2017 ; first published online 20 March 2017

Address for correspondence:

Lis Bodil Karlsson,

Department of Social Work,

Stockholm University, 10691 Stockholm, Sweden

E-mail: lis-bodil.karlsson@socarb.su.se 